\title{
Gastrointestinal Immune Responses in HIV Infected Subjects
}

\section{LRR Castello-Branco ${ }^{+}$, DJM Lewis*, MB Ortigão-de-Sampaio, GE Griffin*}

\author{
Departamento de Imunologia, Instituto Oswaldo Cruz, Av. Brasil 4365, 21045-900 Rio de Janeiro, RJ, Brasil \\ *Division of Infectious Diseases, St. George's Hospital Medical School, London, UK
}

The gut associated lymphoid tissue is responsible for specific responses to intestinal antigens. During HIV infection, mucosal immune deficiency may account for the gastrointestinal infections. In this review we describe the humoral and cellular mucosal immune responses in normal and HIV-infected subjects.

Key words: gastrointestinal tract - HIV - mucosal immunology - immunity to HIV

\section{GASTROINTESTINAL IMMUNOLOGY}

Intestinal mucosal defence is dependent on a number of non specific factors, including gastric acidity, normal bowel flora, intraluminal proteases, peristalsis, goblet cell mucus and a normal enterocyte membrane composition. Changes or disruption of any of these normal non specific defence mechanisms may influence the uptake of intestinal macromolecules and antigens. The gut associated lymphoid tissue (GALT) provides a second line of protection in which cells and antibodies are specifically directed against mucosal pathogens and antigens. GALT is responsible for specific responses to antigens, through its components: secretory $\operatorname{IgA}$, interstitial $\operatorname{IgA}, \operatorname{IgG}, \operatorname{IgM}$ and cellmediated immunity (Castello-Branco 1993).

GALT is composed of organized lymphoid follicles (Peyer's patches in the distal ileum and lymphoid aggregates in the colon), antigen presenting cells and lymphocytes within the lamina propria, intraepithelial lymphocytes and mesenteric lymph nodes. Such lymphoid tissue within the lamina propria constitutes the most important mediator organ of specific humoral immunity in the intestine. There are about $10^{10}$ immunoglobulin producing cells per metre of human small bowel (Brandtzaeg et al. 1987), this is four fold the total amount of such cells determined for bone marrow, spleen, and lymph nodes.

Peyer's patches in the intestinal mucosa are a major source of precursor IgA-producing cells and Peyer's patch T cells have a specialized role in regulating the production of IgA by Peyer's patches

${ }^{+}$Corresponding author. Fax: 55-21-280.1589

Received 7 December 1995

Accepted 10 January 1996
B cells. The intraepithelial T lymphocyte population is predominantly CD8 positive in contrast with the lamina propria where the majority of lymphocytes are CD4 positive (Doe 1989).

Peyer's patches and colonic lymphoid aggregates have a specialized epithelium which facilitates controlled uptake of antigens for induction of mucosal immune responses. The epithelium above Peyer's patches is characterized by a decrease in epithelial cell and brush border height, lack of goblet cells, decrease in surface mucus coat, absence of secretory component and the presence of M cells (Wolf 1988). M cells (membranous or microfold) are specialized epithelial cells which provide physiological portal of entry for luminal antigens, which are non-selectively endocytosed and transported to adjacent lymphocytes, macrophages and dendritic cells. $M$ cells are relatively rare and fail to express HLA-DR, secretory component, or lysosomes (Brandtzaeg \& Bjerke 1990).

Mucosal lymphocytes stimulated by antigen presentation, and $\mathrm{T}$ cell cytokines, migrate to the circulation and return, after maturation, to the mucosal immune system (Castello-Branco 1993). Antigen-stimulated lymphocytes migrate first to mesenteric lymph nodes and then to the systemic circulation via the thoracic duct, following which they home to disseminated mucosal surfaces (McDermott et al. 1986). This homing mechanism is mediated by interaction between an adhesion molecule on the surface of the lymphocyte and a surface molecule at high endothelial venules.

The principal determinant of humoral immunology in humans is secretory $\operatorname{Ig}$ A. Human $\operatorname{IgA}$ exists in two subclasses, IgA1 and $\operatorname{IgA} 2$, which occur in different proportions in serum (80-90\% $\operatorname{IgA} 1)$ and secretions (30-50\% $\operatorname{IgA} 2)$ (Mestecky \& Russel 1986).

The majority of gastrointestinal immunocytes form $J$ chain containing dimers or larger polymers 
of IgA. Such polymeric IgA (pIgA) can be transported through glandular epithelium with a polymeric Ig receptor called secretory component. Secretory component is a glycolipid molecule synthesized by epithelial cells in secretory glandular tissue and mucosal surfaces. The daily output of SIgA exceeds that of all other immunoglobulins combined, and $\operatorname{Ig} \mathrm{A}$ is the major immunoglobulin class in the intestinal secretions. Serum IgA is synthesized largely in the bone marrow, whereas SIgA is produced by plasma cells resident in the submucosa of secretory epithelia and in the glandular stroma (Russel \& Mestecky 1988). B lymphocytes that are primed by gut antigens in Peyer's patches subsequently migrate to the intestinal lamina propria and differentiate into IgA-secreting cells (Kagnoff 1987).

\section{HIV AND THE GASTROINTESTINAL TRACT}

That a mucosal immune deficit occurs during HIV infection is manifest by the frequency and extent of associated - especially gastrointestinal mucosal infections. Whereas acute weight loss in AIDS is more often associated with non gastrointestinal infections such pneumonia, opportunistic infection of the small intestine characteristically causes chronic disease with diarrhoea and malabsorption, and around $70 \%$ of chronic weight loss is associated with gastrointestinal infection and diarrhoea (Macallan et al. 1993). Opportunistic parasitic gut infections cause severe diarrhoea and profoundly compromised small bowel absorptive function (Kapembwa et al. 1990) and cause significant mortality in AIDS both in Western (Levine et al. 1991) and developing countries (Gilks et al. 1990). A frequent absence of pathogens and small bowel villous atrophy (Miller et al. 1988) resembling graft-versus-host disease suggest that immune-mediated responses within the mucosa may also be involved.

\section{GASTROINTESTINAL IMMUNE RESPONSES TO HIV}

The intestinal and respiratory mucosal are the major portal of entry for pathogens and it is therefore not surprising that in immunodeficiency states such pathogens cause significant disease. Specific defects in mucosal immunity are now beginning to be apparent in discrete models of immunodeficiency. In this respect, HIV infection has proved to be important in providing insights into mucosal immunity (Mestecky \& Jackson 1994). For example, intestinal infection with Cryptosporidium $\mathrm{sp}$. is a major cause of morbidity in clinically advanced HIV infection; a recent study (Benhamou et al. 1995) has demonstrated an inefficacy of intestinal secretory immune response to this enteropathogen in AIDS, even though there were detectable specific serum antibodies to this enteropathogen. A paradox of clinical infection has been the demonstration of hypergammaglobulinaemia in the face of advanced disease and deteriorating immune function which is inversely correlated to peripheral blood CD4 count. Both $\operatorname{Ig} \mathrm{A} 1$ and $\operatorname{Ig} \mathrm{A} 2$ subclass concentrations have been demonstrated to be elevated and the presence of IgA from gut mucosal origin has been detected in serum (Quesnel et al. 1994a). This study probably represents a generalized B-cell stimulation secondary to Il-6 drive since this cytokine is thought to be constitutively expressed in advanced HIV infection. Cytokine production has been shown to be disregulated in intestinal mucosa of patients with HIV infection with the tendency towards the production of proinflammatory cytokines (McGowan et al. 1994). The failure of intestinal immunity has previously received attention in adults (Eriksson et al. 1993, Lewis et al. 1994). A recent study has now shed important light on the development of impaired gut mucosal immunity in children (Quesnel et al. 1994b). Impaired intestinal immunity was evident very early in the course of paediatric HIV infection as demonstrated by serum parameters, but local mucosal antibody production or response to enteral vaccines was not investigated.

The production of mucosal antibodies against HIV is likely to be crucial in the protection induced by vaccines against HIV, both in the intestinal and genital tracts. The mucosal immune response to HIV per se is of great pathophysiological significance in the course of HIV infection and a recent study in Zambian patients (Mathewson et al. 1995) has focused on secretory IgA response to p24 during acute and chronic diarrhoea. In this study, a secretory IgA to HIV antigens was demonstrated, but its functional role in enteropathy or the nature of the response was not clearly elucidated. The response may represent an anamnestic response in the face of mucosal stimulation by a secondary enteropathogen. A correlation of specific enteropathogen secretory IgA production with HIV disease progression will be an interesting development of this study. A parallel study (Janoff et al. 1994) examined antibody levels in intestinal fluids from HIV infected individuals and demonstrated aberrant mucosal antibody responses and decreased integrity of the mucosal barrier.

The course of HIV is accompanied by weight loss, malnutrition and trace-element deficiency, particularly in the later stages of the disease. It is therefore often impossible to ascribe primary or secondary aetiological roles to immunodeficiency caused by HIV per se or to accompanying malnu- 
trition. The profound role of nutrition in relation to intestinal tract has recently been summarized (Ferguson 1994) and the specific importance of intraluminal nutrition in the maintenance of intestinal mucosal immunity demonstrated in an animal model (Serizawa et al. 1994).

To exploit fully the potential of the gut for the induction and the dissemination of mucosal and systemic immunity, and better to treat pathological gut inflammatory responses or immunodeficiency states will require a detailed knowledge of the cellular cytokine control mechanisms unique to the mucosal immune system. This is gradually being elicited for the rodent model, but extrapolation to humans may not always be valid; further studies in humans are mandatory.

\section{MUCOSAL IMMUNE RESPONSES FOLLOWING ORAL IMMUNIZATION IN HIV-INFECTED SUB- JECTS}

We have studied mucosal immune responses using the potent cholera toxin B subunit (CTB) (Holmgren et al. 1987), initially defining kinetics and antibody class/subclass of circulating B-cell and antibody responses, and kinetics and phenotype of circulating T-cell responses in healthy volunteers after primary and booster oral immunization. A boostable IgG (mainly IgG1) and IgA (mainly IgA1) circulating B cell response occurs, peaking on day 7 after primary and day 5 after booster oral immunization (Lewis et al. 1991, 1993a), as well as a serum IgG and IgA response (to conformational epitopes on the B subunit pentamer) (Lewis et al. 1993b). A circulating CD4+T-cell response (Castello-Branco et al. 1994, 1995) peaking on days 10-25 but detected up to year later, is also seen. Thus oral CTB, a potent, non-living oral immunogen is a good model to investigate mucosal immune responses in HIV.

We studied British HIV positive homosexual men (with advanced - mean CD4 counts $52 / \mathrm{mm}^{3}$ ), and HIV-infected and uninfected female workers in Nairobi, Kenya (Lewis et al. 1994), at all stages of disease, divided into two groups (CD4 count < $400 / \mathrm{mm}^{3}$ and $>400 / \mathrm{mm}^{3)}$ with mean CD4 counts of 186 and $752 / \mathrm{mm}^{3}$, respectively. After oral immunization with $\mathrm{CTB}$, the African high CD4 group had primary and booster serum IgG and IgA responses equivalent to those of healthy English HIV negative subjects. In contrast, the African low CD4 group had a poor primary response, but booster oral immunization gave equivalent $\operatorname{IgG}$ and $\operatorname{IgA}$ antibody levels to healthy English subjects. Unlike the English subjects, Africans are exposed to LT of enteropathogenic Escherichia coli, and probably have a recall response. The immunodeficient English HIV positive homosexual men had no sig- nificant response to primary or booster oral immunization. Circulating spontaneously secreting anti-CTB IgG and IgA plasmablasts were detected in African HIV infected subjects, and numbers correlated with surrogate markers of disease $\beta 2$ microglobulin and CD4 cell count. Early data suggests that a preserved IgM plasmablast response may occur, but this requires confirmation with more subjects. Although mucosal immunodeficiency does develop, the mucosal system seems able to respond well to oral immunogens until relatively late in HIV disease. We are now characterizing in Brazilian patients the clinical stage at which mucosal immunodeficiency occurs and studying $\mathrm{T}$ cell responses and the mucosal level more directly in terms of $\mathrm{T}$ cell subsets and secretory $\operatorname{IgA}$ responses.

\section{REFERENCES}

Benhamou Y, Kapel N, Hoang C, Matta H, Meillet D, Magne D, Raphael M, Gentilini M, Opolon P, Gobert JG 1995. Inefficacy of intestinal secretory immune response to Cryptosporidium in acquired immunodeficiency syndrome. Gastroenterology 108: 627-635.

Brandtzaeg P, Bjerke K 1990. Immunomorphological characteristics of human Peyer's patches. Digestion 46: 262-273.

Brandtzaeg P, Bjerke K, Kett K 1987. Production and secretion of immunoglobulins in the gastrointestinal tract. Ann Alerg 59: 21-39.

Castello-Branco LRR 1993. Study of Humoral and Cellular Responses to Vibrio cholerae Antigens - A Model to Study Human Gastrointestinal Immunology. $\mathrm{PhD}$ thesis University of London. 115pp.

Castello-Branco LRR, Griffin GE, Dougan G, Lewis DJM 1995. A method to screen T lymphocyte epitopes after oral immunization of humans: application to cholera toxin B subunit. Vaccine 13: 817 820.

Castello-Branco LRR, Griffin GE, Poulton TA, Dougan G, Lewis DJM 1994. Characterization of the circulating $\mathrm{T}$ cell response after oral immunization of humans volunteers with cholera toxin B subunit. Vaccine 12: 65-72.

Doe WF 1989. The intestinal immune system. Gut 30: 1679-1685.

Eriksson K, Kilander A, Hagberg L, Norkrans G, Holmgren J, Czerkinsky C 1993. Intestinal antibody responses to oral vaccination in HIV-infected individuals. AIDS 7: 1087-1091.

Ferguson A 1994. Immunological functions of the gut in relation to nutritional state and mode of delivery of nutrients. Gut 35(suppl 1): S10-S12.

Gilks CF, Brindle RJ, Otieno LS 1990. Life-threatening bacteraemia in HIV-1 seropositive adults admitted to hospital in Nairobi, Kenya. Lancet 336: 545-549.

Holmgren J, Svennerholm AM, Clemens J, Sack D, Black R, Levine M 1987. An oral B subunit-whole cell vaccine against cholera: from concept to successful field trial. Adv Exp Med Biol 216: 1649-1660. 
Janoff EN, Jackson S, Wahl SM, Thomas K, Peterman JH, Smith PD 1994. Intestinal mucosal immunoglobulins during human immunodeficiency virus type 1 infection. J Infect Dis 170: 299-307.

Kagnoff MF 1987 Antigen handling by intestinal mucosa: humoral and cell mediated immunity, tolerance, and genetic control of local immune responses, p.74-93. In Marsh NN, Immunopathology of the small intestine. John Wiley \& Sons Ltd, New York.

Kapembwa MS, Bridges C, Joseph AE, Fleming SC, Batman P, Griffin GE 1990. Ileal and jejunal absorptive function in patients with AIDS and enterococcidial infection. J Infect 21: 43-53.

Levine WC, Beuhles JW, Bean NH, Tauxe RV 1991. Epidemiology of nontyphoidal Salmonella bacteraemia during the human immunodeficiency virus epidemic. J Infect Dis 164: 81-87.

Lewis DJM, Cardosa MJ, Poulton TJ, Castello-Branco LRR, Griffin GE 1993b. Effect of conformation and subunit structure of cholera toxin on antibody binding after oral immunization. J Med Microbiol 38: S293

Lewis DJM, Castello-Branco LRR, Novotny P, Dougan G, Poulton TA, Griffin GE 1993a. Circulating cellular immune response to oral immunization of humans with cholera toxin B subunit. Vaccine 11: 119121.

Lewis DJM, Gilks CF, Ojoo S, Castello-Branco LRR, Dougan G, Evans M, McDermott S, Griffin GE 1994. The immune response following oral administration of cholera toxin N subunit to HIV-1 infected United Kingdom and Kenyan subjects. AIDS 8: 779785.

Lewis DJM, Novotny P, Dougan G, Griffin GE 1991. The early cellular and humoral immune response to primary and booster oral immunization with cholera toxin B subunit. Eur J Immunol 21: 2087-2094.

Macallan DC, Noble C, Baldwin C, Foskett M, McManus T, Griffin GE 1993. Prospective analysis of patterns of weight change in stage IV human immunodeficiency virus infection. AM J Clin Nutr 58: 417-424.
Mathewson JJ, Jiang ZD, Dupont HL, Chintu C, Luo N, Zumla A 1995. Intestinal secretory immunoglobulin A immune response against human immunodeficiency virus among infected patients with acute and chronic diarrhoea. J Infect Dis 169: 614-617.

McDermott MR, Horsewood P, Clark DA, Bienenstock J 1986. T lymphocytes in the intestinal epithelium and lamina propria of mice. Immunology 57: 213218.

McGowan I, Radford SG, Jewell DP 1994. Cytokine gene expression in HIV-infected intestinal mucosa. AIDS 8: 1569-1575.

Mestecky J 1987. The common mucosal immune system and current strategies for induction of immune responses in external secretions. J Clin Immunol 7: 265-276.

Mestecky J, Jackson S 1994. Reassessment of the impact of mucosal immunity in infection with the human immunodeficiency virus (HIV) and design of relevant vaccines. J Clin Immunol 14: 259-272.

Mestecky J, Russel MW 1986. IgA sub-classes, p. $277-$ 301. In S Karger, Monographs in allergy, Basel.

Miller AR, Griffin GE, Batman P 1988. Jejunal mucosal architecture and fat absorption in male homosexuals infected with immunodeficiency virus. $Q \mathrm{~J} \mathrm{Med}$ 69: 1009-1019.

Quesnel A, Moja P, Blanche S, Griscelli C 1994b. Early impairment of gut mucosal immunity in HIV-1-infected children. Clin Exp Immunol 97: 380-385.

Quesnel A, Moja P, Lucht F, Touraine JL, Pozzetto B, Genin C 1994a. Is there immunoglobulin A of gut mucosal origin in the serum of HIV1 infected patients? Gut 35: 803-808.

Russel MW, Mestecky J 1988. Induction of the mucosal immune response. Rev Infect Dis 10: 440-446.

Serizawa H, Miura S, Tashiro H, Imaeda H, Shiozaki H, Ohkubo N, Kimura, H, Tanaka S, Tsuchiya M 1994. Alteration of mucosal immunity after long-term ingestion of an elemental diet in rats. J Parenter Enteral Nutr 18: 141-147.

Wolf JF 1988. The membranous epithelial (M) cell: a portal of antigen entry, p. 75-85. In Inflammatory Bowel Disease. Lea \& Febiger, Philadelphia. 